\title{
Functional recovery in post-stroke patients on hemodialysis during the convalescent phase: a comparison with those not undergoing hemodialysis
}

Takeki Ishida ${ }^{1 *} \mathbb{D}$, Kenichi Kono ${ }^{1}$, Yuusuke Nishida ${ }^{1}$ and Masahiro Yoshida ${ }^{2}$

\begin{abstract}
Background: Low physical fitness is often found in patients undergoing hemodialysis. It may be possible that the recovery of impaired motor function with rehabilitative training might be affected when the patient is on hemodialysis. So far, however, no researcher has clinically investigated this issue in post-stroke patients. The purpose of this study is to clarify the difference of functional recovery during the convalescent phase between post-stroke patients with and without hemodialysis.

Methods: A cohort of 82 post-stroke hemiparetic patients who were admitted to our rehabilitation hospital, were subjected. On the day of admission and discharge, some clinical parameters including Functional Independence Measure (FIM) and Functional Ambulation Category (FAC) were evaluated for each patient. The changes during the hospitalization and the values at the discharge in these parameters were statistically compared between the patients with and without hemodialysis.

Results: The FIM motor score at the discharge was significantly lower in hemodialysis patients than nonhemodialysis patients $(64.7 \pm 21.2$ points in hemodialysis patients and $81.8 \pm 28.0$ points in non-hemodialysis patients, $p<0.05)$. In addition, the frequency of FAC at the discharge of $\geq 3$ was significantly lower in hemodialysis patients than non-hemodialysis patients (40.0\% in hemodialysis patients and $72.2 \%$ in nonhemodialysis patients, $p<0.05$ ).

Conclusion: In patients undergoing hemodialysis seem to experience a worse functional recovery during the convalescent phase compared to those not undergoing hemodialysis. We might have to modify the rehabilitative program during the convalescent phase after stroke if the patient was on hemodialysis.
\end{abstract}

Keywords: Rehabilitation, Stroke, Hemodialysis, Walking ability, Chronic renal failure

\footnotetext{
* Correspondence: 17s3008@g.iuhw.ac.jp

The study was registered with the UMIN Clinical Trials Registry (UMIN000042273).

'Department of Physical Therapy, School of Health Sciences at Narita,

International University of Health and Welfare, 4-3 Kozunomori, Narita, Chiba 286-8686, Japan

Full list of author information is available at the end of the article
}

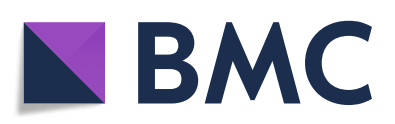

(- The Author(s). 2021 Open Access This article is licensed under a Creative Commons Attribution 4.0 International License, which permits use, sharing, adaptation, distribution and reproduction in any medium or format, as long as you give appropriate credit to the original author(s) and the source, provide a link to the Creative Commons licence, and indicate if changes were made. The images or other third party material in this article are included in the article's Creative Commons licence, unless indicated otherwise in a credit line to the material. If material is not included in the article's Creative Commons licence and your intended use is not permitted by statutory regulation or exceeds the permitted use, you will need to obtain permission directly from the copyright holder. To view a copy of this licence, visit http://creativecommons.org/licenses/by/4.0/. The Creative Commons Public Domain Dedication waiver (http://creativecommons.org/publicdomain/zero/1.0/) applies to the data made available in this article, unless otherwise stated in a credit line to the data. 


\section{Background}

Currently, it is estimated that there are more than 330, 000 patients with hemodialysis due to diabetic nephropathy, chronic glomerulonephritis, and nephrosclerosis [1]. The deterioration of renal function is often associated with not only the decrease of physical fitness but also the loss of muscle mass in the body [2-4]. In addition, it is not uncommon that stroke occurs in the patients undergoing maintenance hemodialysis $[5,6]$. In such cases, the efficacy of rehabilitative training can be impaired, since the improvement of physical fitness and the increase in muscle mass cannot be easily achieved in the patients undergoing hemodialysis [7]. However, so far, no researcher clinically investigated this issue in post-stroke patients. It may be possible that functional recovery in post-stroke patients on hemodialysis is worse compared to those not undergoing hemodialysis. Therefore, the purpose of this study is to clarify the difference of functional recovery during the convalescent phase between post-stroke patients with and without hemodialysis.

\section{Methods}

\section{Subjects}

The study protocol was approved by the ethics committee of International University of Health and Welfare Ichikawa Hospital and informed consent was obtained from the all patients (ID number of 46). The study design was approved by the appropriate ethics review board and conforms to the provisions of the Declaration of Helsinki (as revised in Tokyo 2004) and its later amendments. Patient information was anonymized and de-identified prior to the analysis of this study. This is a retrospective analysis of a prospectively enrolled consecutive cohort of patients who were admitted to our convalescent rehabilitation ward in order to receive long-term rehabilitative training during the period between October 2, 2013, and January 25, 2017. Inclusion criteria for this study were as follows: (1) Patients with a diagnosis of stroke, (2) hemiparesis at the admission to our ward, (3) walking disturbance due to the hemiparesis (in need of a cane, some assistance of a wheelchair), (4) age at the admission between 18-100 years, (5) time between the stroke onset and the admission to our ward of less than 90 days, (6) history of a single stroke only, (7) no active physical or mental illness requiring acute medical management, and (8) no significant disturbance of consciousness at the admission.

The convalescent (Kaifuku-ki) rehabilitation ward provides interdisciplinary sub-acute rehabilitative training for patients requiring assistance in activities of daily living (ADL) after acute hospitalization. Patients with stroke are eligible for the admission to the convalescent rehabilitation ward. For the studied post-stroke patients, rehabilitative training such as physical therapy, occupational therapy, and speech-swallowing therapy was provided daily during their hospitalization. Usually, total duration of rehabilitative training was $2-3 \mathrm{~h}$ a day [8]. As physical therapy, according to their severity of hemiparesis, muscle strengthening training, basic movement training, sitting training, standing training, and walking training were mainly provided. As an occupational therapy, task-specific training (ADL training) was mainly provided. Task-specific training is defined as subjects practice context-specific motor tasks and receive some form of feedback [9]. In rehabilitation, task-specific training focuses on improvement of performance in functional tasks through goal-directed practice and repetition [10].

\section{Clinical assessment}

Clinical evaluation was performed at the admission to our ward and at the discharge of the ward. Following data such as, age gender, time between onset and admission, subtype of stroke, side of hemiparesis, body mass index (BMI), some hematological data (hemoglobin, albumin, CRP, eGFR), and comorbidities were collected at the time of admission. In addition, FIM score, Geriatric Nutritional Risk Index (GNRI), grip strength, Functional Ambulation Category (FAC), and modified Rankin Scale $(\mathrm{mRS})$ were also evaluated at the admission. The FIM consists of 18 categories of disability evaluation and each category is rated on a 7-point scale. The sub-total summed scores of motor and cognitive subscales (FIM motor and cognitive score) are used to quantify functional independence. At admission, for the evaluation of nutritional status, GNRI was calculated based on the serum albumin level and body weight by using the following equation [11]. Grip strength was measured using a Smedley dynamometer (Grip-D, TAKEI, Niigata, Japan) for the non-paralyzed side. Subjects were maintained in a sitting position, with their elbows flexed to $90^{\circ}$ with a neutrally rotated forearm. The maximal grip strength in kilograms was recorded from 3 trials in the non-paralyzed side. FAC assesses ambulation status by determining how much human support the patient requires when walking. This 6-grade scale ranges from independent walking outside (category 5) to nonfunctional walking (category 0). A score of 3 on the scale indicates that a patient can walk only with verbal supervision or guarding. A score of 4 or 5 describes an independent ambulator. Therefore, if the category is $\geq 3$, the patient can be considered able to walk without any assistance. At the time of discharge, FIM score, FAC, and $\mathrm{mRS}$ were evaluated, and the change in these parameters during the hospitalization were assessed.

In this study, the study subjects were divided into two groups such as hemodialysis group and non- 
hemodialysis group. A patient was classified into hemodialysis group when the patient had been continuously on hemodialysis for at least 12 months before the admission and received regularly hemodialysis during the hospitalization to our ward. Usually, 3-4 h session of hemodialysis was provided 3 times a week at the Department of Nephrology at our hospital. We proposed rehabilitative program for the patients so that the intensity and the duration of rehabilitative training could not be different between the two groups. For the patients on hemodialysis, however, rehabilitative program on the day of dialysis was modified. On the day of dialysis, averagely, rehabilitative training was provided for $40 \mathrm{~min}$ before the beginning of the dialysis. In some cases, rehabilitative training was skipped on the day of hemodialysis. All other studied patients not undergoing hemodialysis was classified into non-hemodialysis group.

\section{Sample size calculation}

The FIM at discharge was the one of primary endpoint of this study, and calculation of the sample size was made based on a previous study that reported functional outcome of stroke patients [12]. Based on $\mathrm{a}=0.05$, power $=0.8$, and effect size $=0.38$, it was calculated that total of 210 patients were needed.

\section{Endpoint and statistical analysis}

Primary outcome measure was FIM and ambulation status evaluated by FAC at the time of discharge. All statistical analyses were performed with the use of SPSS version 23.0 (SPSS Inc., Chicago, IL, USA). We performed Kolmogorov-Smirnov test to assess the normality of the datasets. Comparison of clinical characteristics and FIM between two groups was tested by unpaired Student's t test, Mann-Whitney U test for each variables and by chi-square test for categorical variables. The extents of the changes in these 2 parameters were compared using unpaired Student's $t$ test. The comparison of the frequency of favorable FAC of $\geq 3$ and $\mathrm{mRS}$ of $\leq 2$ at the discharge was performed using chi-square test. For this study, a $\mathrm{p}$ value less than 0.05 was considered statistically significant.

\section{Results}

The flowchart of this study is displayed in Fig. 1. In total, for this study, 82 post-stroke hemiparetic patients were included. Among these patients, 10 patients (hemodialysis group) had been on hemodialysis before the admission to our ward and were on hemodialysis during the hospitalization in our ward. The other $72 \mathrm{pa}-$ tients (non-hemodialysis group) did not undergo any hemodialysis treatment. All the patients in hemodialysis group received treatment session of 3-4 h hemodialysis three times a week during their admission to our ward. In the comparison of baseline clinical characteristics between two groups, as shown in Table 1, no significant difference was found in age, gender, BMI, time between onset and admission, length of stay at hospital, subtype of stroke, side of hemiparesis, and comorbidities $(p>$ 0.05). Similarly, hematological date and physical ability date are displayed in Table 2. Hemoglobin, albumin, eGFR, GNRI, and grip strength at admission were significantly lower in hemodialysis group than nonhemodialysis group $(p<0.05)$. No patient experienced any severe complications associated with hemodialysis during the admission. Table 2 shows functional recovery in hemodialysis groups and non-hemodialysis groups. Hemodialysis group had lower FIM total and cognition score at discharge than non-hemodialysis group, but there were a non-statistically significance between both groups $(p>0.05)$. In hemodialysis group, on the other hand, FIM motor score was significantly lower than non-hemodialysis group $(p<0.05)$. There were no significant differences in gain of FIM total, FIM motor, and FIM cognition between both groups $(p>0.05)$. Hemodialysis group had lower FAC at discharge and gain of FAC than non-hemodialysis group, but there were a non-statistically significance between both groups $(p>0.05)$. Furthermore, there was no significant difference in frequency of $\mathrm{mRS} \leq 2$ at discharge in both groups $(p>0.05)$. Although frequency of FAC $\geq 3$ at discharge was significantly lower in hemodialysis group than non-hemodialysis group $(p<0.05)$.

\section{Discussion}

To the best of our knowledge, this is the first clinical study which investigated the difference in the functional recovery between post-stroke patients with and without hemodialysis. Previous study have demonstrated that $60 \%$ of the patients are able to walk independently after stroke. [13]. Kutner et al. found that hemodialysis patients who are unable to walk had a particularly high mortality rate [14]. Therefore, we believe that regaining gait is one of the important goals in the rehabilitation of stroke patients undergoing hemodialysis. Among our patients, no adverse event associated with the introduction of rehabilitation training was found. Smart et al. [15] showed that exercise training is safe for hemodialysis patients. Forrest [7] reported that rehabilitation services appear to be beneficial for the inpatients undergoing hemodialysis. It seems that the rehabilitative training in convalescent rehabilitation ward can be considered to be a safe and feasible intervention for post-stroke patients undergoing hemodialysis.

The present study revealed that post-stroke patients undergoing hemodialysis had lower grip strength and lower GNRI than those not undergoing hemodialysis. 


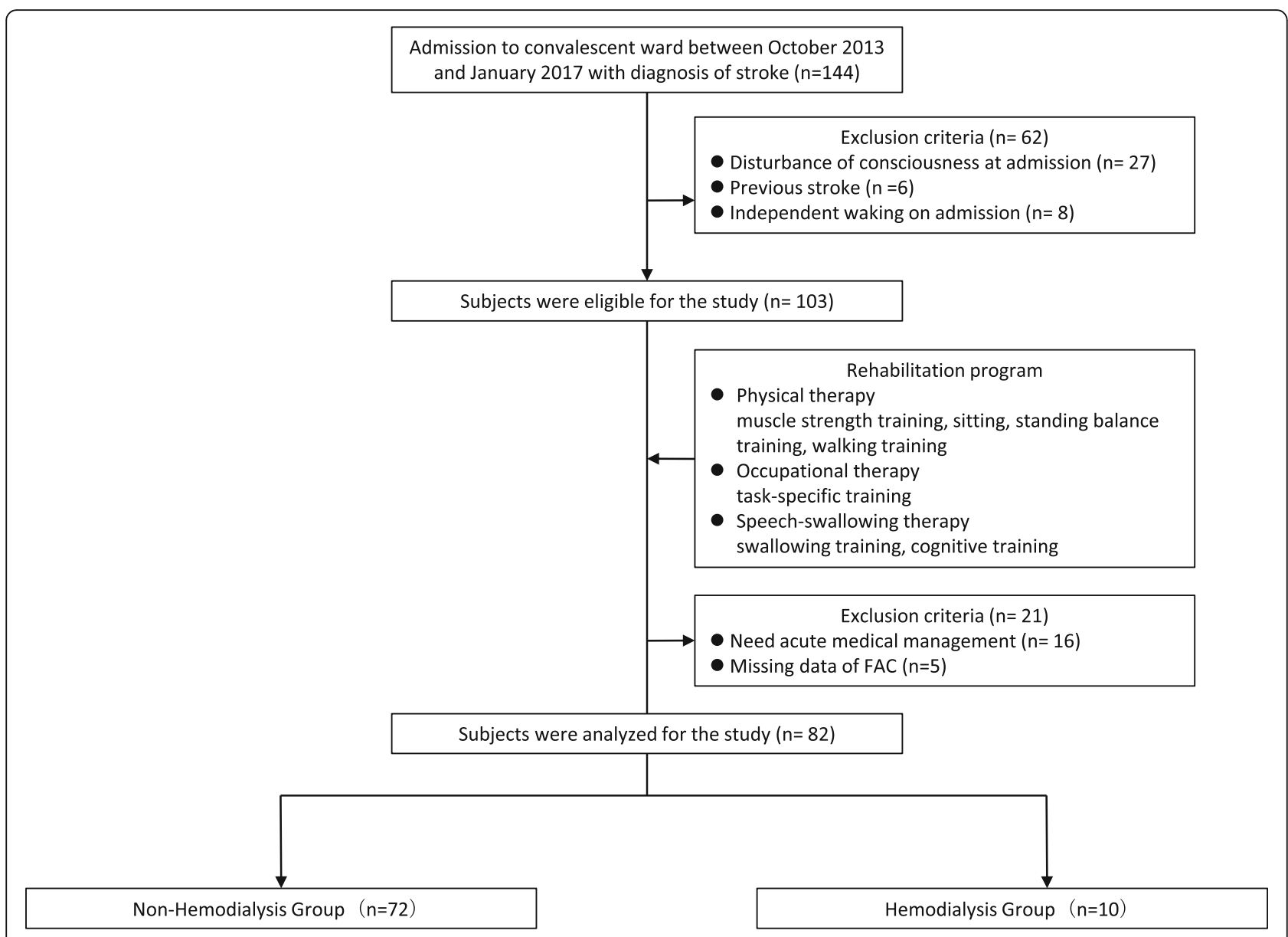

Fig. 1 Flowchart of the study. FAC, functional ambulation category

Johansen et al. [16] showed that hemodialysis patients had lower muscle strength than healthy subjects. Therefore, the results of this study are considered compatible with these previous studies. Isoyama et al. [17] reported that higher serum concentration of inflammatory cytokines such as CRP is associated with lower muscle strength. Kim et al. [18] investigated that hemodialysis patients had lower physical activity compared to healthy subjects and that low physical activity are associated with low muscle strength in hemodialysis patients. Furthermore, Montazerifar et al. [19] showed that serum levels of albumin were significantly lower in hemodialysis patients than in healthy subjects. We speculate that higher inflammatory cytokines, lower physical activity, and malnutrition may have lowered muscle strength in hemodialysis patients before stroke onset.

Post-stroke patients undergoing hemodialysis had lower FIM-motor score at discharge compared to poststroke patients not undergoing hemodialysis. In addition, the frequency of the patient who had regained walking ability (FAC $\geq 3)$ at discharge was significantly lower in post-stroke patients undergoing hemodialysis than in post-stroke patients not undergoing hemodialysis. Only few studies have investigated the functional recovery of hospitalized patients with chronic kidney disease. Forrest [7] investigated the recovery of ADL in hemodialysis patients hospitalized in a rehabilitation hospital and revealed that functional recovery was significantly slower in the patients undergoing hemodialysis than in those not undergoing hemodialysis. Power [5] has reported that the dialysis treatment itself may influence the recovery from acute stroke. These findings suggest that hospitalized patients with hemodialysis are less likely to recover their physical ability, which is in accordance with our study findings. Previous studies have reported that neurological severity and muscle strength can predict the walking ability and ADL at discharge in stroke patients [20-23]. Post-stroke patients with hemodialysis may have not only lower muscle strength but also more severe neurological symptoms compared to post-stroke 
Table 1 Clinical characteristics of studied patients

\begin{tabular}{|c|c|c|c|c|c|}
\hline & & $\begin{array}{l}\text { All patients } \\
(n=82)\end{array}$ & $\begin{array}{l}\text { HD group } \\
(n=10)\end{array}$ & $\begin{array}{l}\text { Non-HD group } \\
(n=72)\end{array}$ & $P$ value \\
\hline \multicolumn{2}{|l|}{ Age, year, mean (SD) } & $71.9(12.7)$ & $68.3(6.5)$ & $72.3(13.3)$ & n.s. \\
\hline \multirow[t]{2}{*}{ Gender, n (\%) } & Females & $38(46.0)$ & $7(70.0)$ & $31(43.0)$ & n.s. \\
\hline & Males & $44(54.0)$ & $3(30.0)$ & $41(57.0)$ & n.s. \\
\hline \multicolumn{2}{|l|}{$\mathrm{BMI}, \mathrm{kg} / \mathrm{m}^{2}$, median (IQR) } & $21.3(18.9-23.9)$ & $19.2(18.1-21.7)$ & $21.4(19.6-23.9)$ & n.s. \\
\hline \multicolumn{2}{|c|}{ Time between onset and admission, day, mean (SD) } & $28.7(11.5)$ & $30.8(6.5)$ & $28.4(12.0)$ & n.s. \\
\hline \multicolumn{2}{|c|}{ Length of stay at hospital, days, mean (SD) } & $85.0(51.0)$ & $107.4(56.1)$ & $72.3(43.2)$ & n.s. \\
\hline \multirow[t]{4}{*}{ Subtype of stroke, n (\%) } & Cerebral infarction & $61(74.3)$ & $5(50)$ & $56(77.8)$ & n.s. \\
\hline & Intracerebral hemorrhage & $15(18.3)$ & $4(40)$ & $11(15.2)$ & n.s. \\
\hline & Subarachnoid hemorrhage & $4(4.9)$ & $0(0)$ & $4(5.6)$ & n.s. \\
\hline & Chronic subdural hematoma & $2(2.5)$ & $1(10)$ & $1(1.4)$ & n.s. \\
\hline \multirow[t]{2}{*}{ Side of hemiparesis, n (\%) } & Right & $32(39.0)$ & $2(20.0)$ & $30(41.6)$ & n.s. \\
\hline & Left & $36(43.9)$ & $8(80.0)$ & $28(38.9)$ & n.s. \\
\hline \multirow[t]{5}{*}{ Comorbidities, n (\%) } & Hypertension & $40(48.8)$ & $7(70.0)$ & $33(45.8)$ & n.s. \\
\hline & Diabetes & $18(22.0)$ & $4(40.0)$ & $14(19.4)$ & n.s. \\
\hline & Heart disease & $20(24.4)$ & $5(50.0)$ & $15(20.8)$ & n.s. \\
\hline & Cancer & $5(6.1)$ & $2(20.0)$ & $3(4.2)$ & n.s. \\
\hline & Orthopedic disease & $6(7.3)$ & $2(20.0)$ & $4(5.6)$ & n.s. \\
\hline \multirow[t]{4}{*}{ Cause of chronic renal failure, n (\%) } & Diabetic nephropathy & & $4(40)$ & & \\
\hline & Polycystic renal disease & & $3(30)$ & & \\
\hline & Chronic glomerulonephritis & & $1(10)$ & & \\
\hline & Others & & $2(20)$ & & \\
\hline
\end{tabular}

HD Group hemodialysis group, Non-HD Group non-hemodialysis group, SD standard deviation, BMI body mass index, IQR interquartile range

patients without hemodialysis. Furthermore, Ormerod et al. [24] demonstrated that arterial stiffness is independently associated with neurologic deficit after acute stroke. On the other hand, brain-derived neurotrophic factor (BDNF) may be lower in post-stroke patients undergoing hemodialysis than post-stroke patients not undergoing hemodialysis. Zoladz et al. [25] compared serum BDNF between hemodialysis patients and healthy adults. The result of their study showed that serum BDNF levels in hemodialysis patients are significantly lower than those in healthy adults. In addition, they found that single hemodialysis treatment reduces serum BDNF concentration in hemodialysis patients. Therefore, it seems that neurologic severity may be higher in poststroke patients undergoing hemodialysis than poststroke patients not undergoing hemodialysis at rehabilitation hospital admission. Furthermore, in this study, post-stroke patients undergoing hemodialysis had lower frequency of rehabilitation on dialysis days than poststroke patients not undergoing hemodialysis patients. It may have inhibited the improvement in walking ability and ADL in post-stroke patients undergoing hemodialysis. Forrest et al. [26] found that the efficiency of ADL is improved by ensuring rehabilitation session on hemodialysis day. A recent meta-analysis showed that efficacy and safety of intradialytic exercise for hemodialysis patient [27]. In the future clinical setting, more sessions of rehabilitation may be desired to be provided for the patients on hemodialysis, including intradialytic exercise.

The present study has some certain limitations. Firstly, this is a retrospective analysis comparing clinical outcome between post-stroke patients with and without hemodialysis. In addition, the number of studied patients was relatively small. Therefore, the results of this study cannot be applied to the general population of hospitalized hemodialysis patients. Secondly, the detailed data regarding walking function and muscle mass is not available for studied patients. For example, 6-min walk test and body composition should have been evaluated serially in the studied patients. Thirdly, we could not investigate which clinical factors can influence the functional outcome in poststroke patients on hemodialysis. It may be interesting to clarify such clinical factors in post-stroke patients with hemodialysis. 
Table 2 Comparison of Hematological date and physical ability

\begin{tabular}{|c|c|c|c|c|c|}
\hline & & $\begin{array}{l}\text { All patients } \\
(n=82)\end{array}$ & $\begin{array}{l}\text { HD group } \\
(n=10)\end{array}$ & $\begin{array}{l}\text { Non-HD group } \\
(n=72)\end{array}$ & $P$ value \\
\hline \multicolumn{2}{|l|}{ Hemoglobin at admission, g/dL, mean (SD) } & $13.1(2.2)$ & $10.2(1.2)$ & $13.5(2.0)$ & $<0.05$ \\
\hline \multicolumn{2}{|l|}{ Albumin at admission, $\mathrm{g} / \mathrm{dL}$, mean (SD) } & $4.0(0.5)$ & $3.3(0.5)$ & $4.1(0.4)$ & $<0.05$ \\
\hline \multicolumn{2}{|l|}{ CRP at admission, mg/dL, median (IQR) } & $0.2(0.1-0.4)$ & $0.2(0.1-0.3)$ & $0.2(0.1-0.4)$ & n.s. \\
\hline \multicolumn{2}{|l|}{ eGFR, mL/min/1.73 m², mean (SD) } & $51.5(28.6)$ & $3.9(1.8)$ & $58.1(23.9)$ & $<0.05$ \\
\hline \multicolumn{2}{|l|}{ GNRI at admission, median (IQR) } & $100.4(92.3-105.4)$ & $88.5(86.8-89.9)$ & $101.6(95.7-105.7)$ & $<0.05$ \\
\hline \multicolumn{2}{|l|}{ mRS at admission, median (IQR) } & $4(3-4)$ & $4(4-4)$ & $4(3-4)$ & n.s. \\
\hline \multicolumn{2}{|l|}{$\mathrm{mRS} \leq 2$ at discharge, $\mathrm{n}(\%)$} & $41(50.0)$ & $3(30.0)$ & $38(52.8)$ & n.s. \\
\hline \multicolumn{2}{|l|}{ Grip strength at admission, kg, mean (SD) } & $20.1(9.1)$ & $13.6(6.0)$ & $20.9(8.8)$ & $<0.05$ \\
\hline \multirow[t]{4}{*}{ FAC } & At admission, median (IQR) & $2(1-3)$ & $1.5(0-2)$ & $2(1-3)$ & n.s. \\
\hline & At discharge, median (IQR) & $4(3-5)$ & $2.5(1.3-3.8)$ & $4(3-5)$ & n.s. \\
\hline & Gain during admission, median (IQR) & $1.0(0.0-2.0)$ & $1.0(0.3-1.0)$ & $1.0(0.0-2.0)$ & n.s. \\
\hline & $\geq 3$ at discharge, $\mathrm{n}(\%)$ & $56(68.2)$ & $4(40.0)$ & $52(72.2)$ & $<0.05$ \\
\hline \multirow[t]{3}{*}{ FIM score at admission, score } & Total mean (SD) & $78.9(20.0)$ & $69.4(23.5)$ & $80.2(28.5)$ & n.s. \\
\hline & Motor mean (SD) & $60.3(28.4)$ & $48.1(20.5)$ & $62.0(29.1)$ & n.s. \\
\hline & Cognition median (IQR) & $24.0(20.0-28.8)$ & $22.0(20.0-24.5)$ & $25.0(20.0-30.3)$ & n.s. \\
\hline \multirow[t]{3}{*}{ FIM score at discharge, score, median (IQR) } & Total & $108.5(90.3-120.0)$ & $94.5(78.0-116.5)$ & $112.5(92.5-121.0)$ & n.s. \\
\hline & Motor & $84.5(66.0-91.0)$ & $67.0(52.0-85.0)$ & $86.0(68.3-94.0)$ & $<0.05$ \\
\hline & Cognition & $30.0(25.3-33.0)$ & $26.5(24.5-30.5)$ & $30.0(25.8-33.0)$ & n.s. \\
\hline \multirow[t]{3}{*}{ FIM gain during Admission, score } & Total mean (SD) & $21.7(15.5)$ & $22.4(13.5)$ & $21.6(15.8)$ & n.s. \\
\hline & Motor mean (SD) & $19.4(14.9)$ & $16.6(10.3)$ & $19.8(15.5)$ & n.s. \\
\hline & Cognition median (IQR) & $4.0(2.0-6.8)$ & $6.0(3.0-8.5)$ & $4.0(1.8-6.0)$ & n.s. \\
\hline
\end{tabular}

HD Group hemodialysis group, Non-HD Group non-hemodialysis group, SD standard deviation, eGFR estimated glomerular filtration rate, GNRI geriatric nutritional risk index, $m R S$ modified Rankin scale, IQR interquartile range, FAC functional ambulation category, FIM functional independence measure

\section{Conclusion}

We clarified the difference in functional recovery between post-stroke patients with and without hemodialysis. The extent of the functional recovery during the convalescent phase was significantly smaller in the patients on hemodialysis compared to those without hemodialysis. We might have to modify the rehabilitative program during the convalescent phase after stroke if the patient was on hemodialysis.

\section{Abbreviations}

ADL: Activities of daily living; BMl: Body mass index; CRP: $C$ reactive protein; eGFR: Estimated glomerular filtration rate; FIM: Functional independence measure; GNRI: Geriatric nutritional risk index; FAC: Functional ambulation category; mRS: Modified Rankin scale; BDNF: Brain-derived neurotrophic factor; HD: Hemodialysis; SD: Standard deviation; IQR: Interquartile range

\section{Acknowledgements}

The authors gratefully acknowledge the support and the participation of the patients in this study.

\section{Authors' contributions}

$\mathrm{TI}, \mathrm{KK}$, and $\mathrm{YN}$ equally contributed to the conception and design of the work; TI, KK, and MY contributed to collection and assembly of data; TI, KK, and YN contributed to analysis and interpretation of data; TI and KK prepared the draft article; the authors read and approved the final manuscript.

\section{Funding}

This study received no specific grant from any funding agency in the public, commercial, or not-for-profit sectors.

\section{Availability of data and materials}

The data will not be shared because the informed consent from subjects regarding the public availability for their data was not obtained.

\section{Declarations}

\section{Ethics approval and consent to participate}

The study protocol was approved by the ethics committee of International University of Health and Welfare Ichikawa Hospital, and informed consent was obtained from the all patients (ID number of 46). The study design was approved by the appropriate ethics review board and conforms to the provisions of the Declaration of Helsinki (as revised in Tokyo 2004) and its later amendments. Patient information was anonymized and de-identified prior to the analysis of this study.

\section{Competing interests}

The authors declare that they have no competing interests.

\section{Author details}

'Department of Physical Therapy, School of Health Sciences at Narita, International University of Health and Welfare, 4-3 Kozunomori, Narita, Chiba 286-8686, Japan. ${ }^{2}$ Department of Hemodialysis and Surgery, International University of Health and Welfare Ichikawa Hospital, Chiba, Japan. 
Received: 6 August 2020 Accepted: 18 May 2021

Published online: 19 June 2021

\section{References}

1. Masakane I, Taniguchi M, Nakai S, et al. Annual dialysis data report 2016, JSDR Renal Data Registry. Jpn J Transplant. 2018;51:1-51.

2. Faria Rde S, Fernandes N, Lovisi JC, et al. Pulmonary function and exercise tolerance are related to disease severity in pre-dialytic patients with chronic kidney disease: a cross-sectional study. BMC Nephrol. 2013;14(1):184. https:// doi.org/10.1186/1471-2369-14-184.

3. Lattanzio F, Corsonello A, Abbatecola AM, Volpato S, Pedone C, Pranno L, et al. Relationship between renal function and physical performance in elderly hospitalized patients. Rejuvenation Res. 2012;15(6):545-52. https:// doi.org/10.1089/rej.2012.1329.

4. Mclntyre CW, Selby NM, Sigrist M, Pearce LE, Mercer TH, Naish PF. Patients receiving maintenance dialysis have more severe functionally significant skeletal muscle wasting than patients with dialysis-independent chronic kidney disease. Nephrol Dial Transplant. 2006;21(8):2210-6. https://doi.org/1 0.1093/ndt/gfl064

5. Power A. Stroke in dialysis and chronic kidney disease. Blood Purif. 2013;36: 79-83.

6. Seliger SL, Gillen DL, Longstreth WT Jr, Kestenbaum B, Stehman-Breen CO. Elevated risk of stroke among patients with end-stage renal disease. Kidney Int 2003:64(2):603-9. https://doi.org/10.1046/j.1523-1755.2003.00101 x.

7. Forrest GP. Inpatients rehabilitation of patients requiring hemodialysis. Arch Phys Med Rehabil. 2004;85(1):51-3. https://doi.org/10.1016/S0003-9993(03 )00366-6.

8. Winstein CJ, Stein J, Arena R, et al. Guidelines for adults stroke rehabilitation and recovery: a guideline for healthcare professionals from the American Heart Association/American Stroke Association. Stroke. 2017:48:e369.

9. Teasell RW, Foley NC, Salter KL, Jutai JW. A blueprint for transforming stroke rehabilitation care in Canada: the case for change. Arch Phys Med Rehabil. 2008:89(3):575-8. https://doi.org/10.1016/j.apmr.2007.08.164.

10. Hubbard IJ, Parsons MW, Neilson C, Carey LM. Task-specific training: evidence for and translation to clinical practice. Occup Ther Int. 2009:16(34):175-89. https://doi.org/10.1002/oti.275.

11. Yamada K, Furuya R, Takita T, Maruyama Y, Yamaguchi Y, Ohkawa S, et al. Simplified nutritional screening tools for patients on maintenance hemodialysis. Am J Clin Nutr. 2008;87(1):106-13. https://doi.org/10.1093/a jen/87.1.106.

12. Mizrahi EH, Waitzman A, Arad M, Adunsky A. Functional outcome of elderly survivors of ischemic stroke: retrospective study comparing non hypercholesterolemic and hypercholesterolemic patients. Isr Med Assoc J. 2011;13:259-99.

13. Preston $E$, Ada $L$, Dean $C M$, Stanton $R$, Waddington $G$. What is the probability of patients who are nonambulatory after stroke regaining independent walking? A systematic reviews. Int J Stroke. 2011;6(6):531-40. https://doi.org/10.1111/j.1747-4949.2011.00668.x.

14. Kutner NG, Zhang R, Huang Y, Painter P. Gait speed and mortality, hospitalization, and functional status change among hemodialysis patients: a US Renal Data System Special Study. Am J Kidney Dis. 2015;66(2):297-304. https://doi.org/10.1053/j.ajkd.2015.01.024.

15. Smart N, Steele M. Exercise training in haemodialysis patients: a systematic review and meta-analysis. Nephrology (Carlton). 2011;16(7):626-32. https:// doi.org/10.1111/j.1440-1797.2011.01471.x.

16. Johansen KL, Shubert T, Doyle J, Soher B, Sakkas GK, Kent-Braun JA. Muscle atrophy in patients receiving hemodialysis: effect on muscle strength, muscle quality, and physical function. Kidney Int. 2003;63(1):291-7. https:// doi.org/10.1046/j.1523-1755.2003.00704.x.

17. Isoyama N, Qureshi AR, Avesani CM, Lindholm B, Bàràny P, Heimbürger $O$, et al. Comparative associations of muscle mass and muscle strength with mortality in dialysis patients. Clin J Am Soc Nephrol. 2014;9(10):1720-8. https://doi.org/10.2215/CJN.10261013.

18. Kim JC, Shapiro BB, Zhang M, Li Y, Porszasz J, Bross R, et al. Daily physical activity and physical function in adult maintenance hemodialysis patients. J Cachexia Sarcopenia Muscle. 2014;5(3):209-20. https://doi.org/10.1007/s1353 9-014-0131-4.

19. Montazerifar F, Karajibani M, Hassanpour Z, Pourmofatteh M. Study of serum levels of leptin. C-reactive protein and nutritional status in hemodialysis patients. Iran Red Crescent Med J. 2015;17:e26880.
20. Yoshimura Y, Wakabayashi H, Bise T, Tanoue M. Prevalence of sarcopenia and its association with activities of daily living and dysphagia in convalescent rehabilitation ward inpatients. Clin Nutr. 2018;37(6):2022-8. https://doi.org/10.1016/j.clnu.2017.09.009.

21. Hiraoka S, Maeshima S, Okazaki H, Hori H, Tanaka S, Okamoto S, et al. Factors necessary for independent walking in patients with thalamic hemorrhage. BMC Neurol. 2017;17(1):211-5. https://doi.org/10.1186/s12883017-0991-2.

22. Hirano Y, Hayashi T, Nitta O, Takahashi H, Nishio D, Minakawa T, et al. Prediction of independent walking ability for severely hemiplegic stroke patients at discharge from a rehabilitation hospital. J Stroke Cerebrovasc Dis. 2016;25(8):1878-81. https://doi.org/10.1016/j.jstrokecerebrovasdis.201 5.12.020.

23. Gialanella B, Santoro R, Ferlucci C. Predicting outcome after stroke: the role of basic activities of daily living predicting outcome after stroke. Eur J Phys Rehabil Med. 2013;49(5):629-37.

24. Ormerod E, Ali K, Cameron J, Malik M, Lee R, Getov S, et al. The association between arterial stiffness, initial stroke severity, and 3-week outcomes in patients with ischemic stroke. J Stroke Cerebrovasc Dis. 2017;26(11):2541-6. https://doi.org/10.1016/j.jstrokecerebrovasdis.2017.05.043.

25. Zoladz JA, Smigielski M, Majerczak J, et al. Hemodialysis decreases serum brain-derived neurotrophic factor concentration in humans. Neurochem Res. 2012;37(12):2715-24. https://doi.org/10.1007/s1 1064-012-0862-6.

26. Forrest G, Nagao M, labal A, Kakar R. Inpatient rehabilitation of patients requiring hemodialysis: improving efficiency of care. Arch Phys Med Rehabil. 2005:86(10):1949-52. https://doi.org/10.1016/j.apmr.2005.04.006.

27. Pu J, Jiang Z, Wu W, Li L, Zhang L, Li Y, et al. Efficacy and safety of intradialytic exercise in haemodialysis patients: a systematic review and meta-analysis. BMJ Open. 2019;9(1):e020633. https://doi.org/10.1136/ bmjopen-2017-020633.

\section{Publisher's Note}

Springer Nature remains neutral with regard to jurisdictional claims in published maps and institutional affiliations.

Ready to submit your research? Choose BMC and benefit from:

- fast, convenient online submission

- thorough peer review by experienced researchers in your field

- rapid publication on acceptance

- support for research data, including large and complex data types

- gold Open Access which fosters wider collaboration and increased citations

- maximum visibility for your research: over $100 \mathrm{M}$ website views per year

At BMC, research is always in progress.

Learn more biomedcentral.com/submissions 